\title{
Clinical features and complications of acromegaly at diagnosis are not all the same: data from two large referral centers
}

\author{
Elena V Varlamov 1,2,3,*, Dan Alexandru Niculescu ${ }^{4, *}$, Swechya Banskota ${ }^{1,2,3}$, Simona Andreea Galoiu ${ }^{4}$, \\ Catalina Poiana ${ }^{4}$ and Maria Fleseriu (1) 1,2,3 \\ ${ }^{1}$ Department of Medicine (Endocrinology, Diabetes and Clinical Nutrition), Oregon Health \& Science University, Portland, Oregon, USA \\ ${ }^{2}$ Department of Neurological Surgery, Oregon Health \& Science University, Portland, Oregon, USA \\ ${ }^{3}$ Pituitary Center, Oregon Health \& Science University, Portland, Oregon, USA \\ ${ }^{4}$ Department of Pituitary and Neuroendocrine Disorders, C. I. Parhon National Institute of Endocrinology, 'Carol Davila' University of Medicine and \\ Pharmacy Bucharest, Romania
}

Correspondence should be addressed to M Fleseriu: fleseriu@ohsu.edu

*(E V Varlamov and D A Niculescu contributed equally to this work)

\begin{abstract}
Purpose: The number of international acromegaly related registries is increasing; however, heterogeneity of acromegaly symptoms and signs across countries is not well described. We compared clinical disease manifestations at diagnosis between two large University referral centers from two continents.

Methods: Retrospective, comparative epidemiological study of acromegaly patients at two centers: (i) C. I. Parhon National Institute of Endocrinology, 'Carol Davila' University of Medicine and Pharmacy Bucharest, Romania (Parhon), and (ii) Pituitary Center, Oregon Health \& Science University, Portland, Oregon, United States (OHSU) from approved data repositories was undertaken. Data were extracted from medical charts and questionnaires. Binary logistic regression analysis was undertaken for the most frequently noted symptoms and clinical signs.

Results: The study included 216 patients (87 Parhon, 129 OHSU). Age, sex, and median delay in diagnosis were similar between centers. IGF-1 index was higher in patients at Parhon (3.3 vs $2.1, P<0.001)$. The top five symptoms at both centers were enlarged hands/feet, headache, arthralgia, fatigue, and irregular menses in women. A significant difference was noted for multiple signs and symptoms frequency, often > 20 percentage points between centers. Center was a predictor of many signs and symptoms,

independent of acromegaly biochemical severity or disease duration.

Conclusion: We show in the first comparative study that differences in medical practice, documentation, and likely cultural differences can influence patients' symptom(s) reporting and screening patterns in geographically different populations. Pooling data into large multicenter international registry databases may lead to loss of regional characteristics and thus a mixed overall picture of combined cohorts.
\end{abstract}

\section{Introduction}

Acromegaly is a rare disease that is caused by excessive growth hormone $(\mathrm{GH})$ secretion by a pituitary adenoma
$(1,2,3)$. The clinical picture of active acromegaly is characterized by a combination of symptoms, signs, and https://ec.bioscientifica.com https://doi.org/10.1530/EC-21-0035 (c) 2021 The authors Published by Bioscientifica Ltd

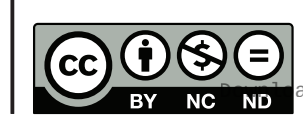

This work is licensed under a Creative Commons Attribution-NonCommercial-NoDerivatives 4.0 enternationad ticense ifica.com at 04/26/2023 09:34:09AM 
comorbidities related to the tumor itself (e.g. headache, oculomotor never palsy or hypopituitarism) or to GH and insulin-like growth factor-1 (IGF-1) excess (arthralgia, morphologic changes, or obstructive sleep apnea (OSA), cardiovascular disease, and secondary diabetes mellitus (DM)) $(2,3,4)$. Long-standing acromegaly is relatively easy to diagnose due to multiple pathognomonic signs and symptoms. However, milder disease cases pose a great challenge, and an acromegaly diagnosis is eventually considered after numerous non-endocrine evaluations. Clinical manifestations are insidious and a diagnosis is usually delayed by $6-10$ years $(5,6,7,8)$; although a few publications reported a shorter time to diagnosis, 2.55.5 years $(9,10,11)$ and a decline of the diagnostic delay overtime (5). Interestingly, in most cases, an evaluation is initiated by primary care providers (PCP) (10).

Several studies have identified a clinical profile that accompanies active acromegaly along with the severity and frequency of various signs, symptoms, and complications, often with vast differences between studies $(4,5,12,13$, $14,15)$. Many investigators, because acromegaly is a rare disease, have attempted to increase the subject number and statistical accuracy by aggregating data from national or international acromegaly data registries $(5,12,16)$. Although the importance of these studies is without question, some have uncovered significant differences between countries and/or centers in the diagnosis and treatment of acromegaly and disease-related complications $(5,16,17)$. This might be one reason for the relative lack of success of studies that have attempted to determine a specific combination of signs and symptoms most indicative of acromegaly $(12,14)$.

While differences in clinical presentation in patients from different countries and centers could be due to genetic variation, other important socio-economic factors such as access to medical care, trust in medical care providers, imaging modalities used, type of IGF- 1 assays, local practice of medicine, provider bias, and cultural factors such as family influence on decision-making, and misconceptions and/or misinterpretations regarding symptoms likely also play a role $(18,19,20,21)$. If these differences are inherent to the studied populations, data pooling into national and international registries might lead to inappropriate result generalization (22), and local relevance could be lost.

We aimed to compare the acromegaly clinical picture, at diagnosis, between two university referral centers: (i) Department of Pituitary and Neuroendocrine Disorders, C. I. Parhon National Institute of Endocrinology, 'Carol Davila' University of Medicine and Pharmacy Bucharest, Romania (Parhon), and (ii) Pituitary Center, Oregon Health \& Science University, Portland, Oregon, United
States (OHSU). We also aimed to assess any differences, and if any such differences were disease-related per se or due to factors such as specific medical practice(s), medical record chart documentation, or culture.

\section{Methods}

\section{Study design and patients}

This is a retrospective, comparative epidemiological study of newly diagnosed and previously untreated acromegaly patients who presented to two university referral centers; Parhon (years; 2012-2020) and OHSU (years; 2006-2018).

Parhon maintains an approved repository of all patients with pituitary adenomas followed by the institution since 1990 . The present cohort includes patients with acromegaly $(n=87)$ assessed before any treatment (years; 2012-2020). Patients presenting prior to 2012 were excluded as IGF-1 measurements were performed with various assays that are no longer in use. Patients assessed after 2012 had serum IGF-1 measured with the same IGF-1 assay.

OHSU maintains an institutional review board approved repository of all patients with pituitary adenomas; those prior to 2006 were not included here due to the transition to electronic medical records (EMR) in 2006.

\section{Clinical evaluation}

At Parhon, patients were clinically assessed by history and clinical examinations; there were no pre-printed questionnaires or checklists. All medical staff working at Parhon have large experience treating acromegaly patients as it is the largest Pituitary Center in Romania serving most of the country's population (23).

At OHSU, the majority of patients were assessed by the same neuroendocrinologist (MF) using a standard acromegaly documentation template in the EMR. A pituitary symptoms questionnaire written in lay terms was completed by patients. Quality of life (QoL) questionnaires were not routinely evaluated at diagnosis and thus, not included.

Data on symptoms and physical exam findings were extracted from clinic chart notes and questionnaires. Age, sex, and delay in diagnosis (determined as time between the first symptom and official diagnosis) were also recorded.

\section{Biochemical evaluation}

Biochemical diagnosis of acromegaly was made based on elevated IGF-1 and/or non-suppressible growth hormone $(\mathrm{GH})$ on oral glucose tolerance test when applicable.

This work is licensed under a Creative Commons Attribution-NonCommercial-NoDerivatives 4.0 Internationab License.ifica. com at 04/26/2023 09:34:09AM 
In Parhon patients, GH and IGF-1 were measured with an automated chemiluminescent analyzer (Liaison XL, Diasorin). Measuring ranges were 3-1500 ng/mL for IGF-1, and $0.05-80 \mathrm{ng} / \mathrm{mL}$ for $\mathrm{GH}$, respectively. At OHSU, the majority of GH and IGF-1 were measured as previously published (24). Growth hormone values that were below the detection limit were reported as the lower limit of normal, and the values that were above the assay reading capacity were reported as the maximum reading capacity (e.g. $\mathrm{GH}>100 \mathrm{ng} / \mathrm{mL}$ was reported as $100 \mathrm{ng} / \mathrm{mL}$ ). Some patients had IGF-1 performed at an outside laboratory and the reference range differed between laboratories.

To normalize the values across the IGF-1assays and adjust for the age- and sex-related differences, IGF-1 values were expressed as IGF-1 index (IGF-1/upper limit of normal (ULN) for each patient). This is a common approach undertaken in most multicenter acromegaly studies, both prospective and retrospective in the absence of a central $\operatorname{lab}(5,12)$.

\section{Imaging evaluation}

In both OHSU and Parhon patients, MRI was performed at various facilities, and the data on tumor size at diagnosis were extracted from imaging reports. Maximum tumor diameter was recorded.

\section{Comorbidity evaluation}

At Parhon, patients' medical history was obtained at presentation, and the following comorbidities were routinely recorded: hypertension, DM, dyslipidemia, arrhythmia, and thyroid nodules. Data on obstructive sleep apnea (OSA), coronary artery disease (CAD), heart failure, colonic polyps, bone mass (by dual-energy X-ray absorptiometry), and spinal fractures were not routinely collected as screening information but were performed as clinically indicated and recorded if a patient mentioned it at the visit. At OHSU, patients' medical history was obtained at presentation and the following comorbidities were recorded: OSA, hypertension, coronary artery disease, heart failure, arrhythmia, DM, dyslipidemia, colonic polyps, thyroid nodules, and spinal fractures. Patients without a history of these comorbidities were referred for sleep study evaluation, echocardiogram (ECHO), colonoscopy, thyroid ultrasound - if a palpable thyroid abnormality was present, and spinal x-rays, and bone mass (by dual-energy X-ray absorptiometry) since 2011. Hemoglobin A1c and lipid panel were either measured or requested to be obtained by a PCP. Prevalence of comorbidities was calculated as the number of patients with identified comorbidity divided by the total number of patients in the cohort.

\section{Statistical analysis}

Statistical analysis was performed using SPSS 25. MannWhitney test was used to evaluate continuous variables (age, delay in diagnosis, IGF-1 index, GH, maximum tumor diameter). Chi-square test was used to evaluate categorical variables (sex, symptoms, and physical exam findings at presentation). Binary logistic regression analysis was performed for symptoms and physical exam findings with the occurrence of $>20 \%$ using center (institution), age, sex, delay in diagnosis, IGF-1 index, and GH as independent predictors. Forward LR stepwise method was utilized.

\section{Results}

Eighty-seven acromegaly patients from Parhon and 129 from OHSU were included. There was no significant difference in age, sex, and median delay in diagnosis between the two centers. Interestingly, the median age in males ( 45 years) at Parhon was 9 years younger than females (54 years) at diagnosis, while males and females at OHSU were diagnosed around the same age (51.5 vs 51 years, respectively). Patients at Parhon presented with significantly higher IGF-1 index $(3.3 \times \mathrm{ULN})$ and nadir $\mathrm{GH}(5.3 \mathrm{ng} / \mathrm{mL})$ compared with OHSU patients $(2.1 \times \mathrm{ULN}$ and $2.1 \mathrm{ng} / \mathrm{mL}$, respectively). There was no difference in random GH levels and tumor diameters (Table 1).

The descending order of the aggregate (Parhon plus OHSU) percentages for reported symptoms were large extremities (66.7\%), headache (59.7\%), arthralgia $(52.8 \%)$, fatigue $(52.3 \%)$, weight gain (35.6\%), snoring (32.9\%), memory loss (29.2\%), frontal bossing (25\%), hirsutism (25\%), jaw changes $(24.5 \%)$, excessive sweating (23.6\%), coarse facies $(21.8 \%)$, skin tags $(21.3 \%)$, carpal tunnel syndrome (20.4\%), round face (19.4\%), back neck pain (19\%), spread teeth $(18.1 \%)$, oily skin (18.1\%), increased nose (17.6\%), and enlarged lips (15.3\%). Loss of libido, peripheral neuropathy, depression, macroglossia, visual defects, acne, constipation, shortness of breath, hyperpigmentation, increased head, galactorrhea, thick skin, and gigantism had an aggregate frequency of $<15 \%$ each.

The descending order of the aggregate (Parhon plus OHSU) percentages for physical exam findings were hand enlargement (68.5\%), frontal bossing (67.6\%), protruding jaw (58.8\%), coarse facies (38.4\%), sweaty or oily skin (37.5\%), skin tags (33.8\%), gaps between teeth (32.4\%), macroglossia

This work is licensed under a Creative Commons Attribution-NonCommercial-NoDerivatives 4.0 Internationad bicense.ifica.com at 04/26/2023 09:34:09AM 
Table 1 Patient baseline characteristics.

\begin{tabular}{|c|c|}
\hline Characteristic & All patients $(n=216)$ \\
\hline Females (\%) & 59.2 \\
\hline Age (years) & $51.0(38.0,61.0)$ \\
\hline Age, females & $52.5(38.0,61.0)$ \\
\hline Age, males & $48.5(39.8,60.0)$ \\
\hline Delay in diagnosis (months) & $60.0(23.8,119.0)$ \\
\hline IGF-1 (ng/mL) & $659(416,948)$ \\
\hline IGF-1 ( $\times$ ULN) & $2.7(1.6,3.7)$ \\
\hline Random GH (ng/mL) & $5.7(2.0,20.7)$ \\
\hline Nadir GH on oral glucose tolerance test $(\mathrm{ng} / \mathrm{mL})$ & $3.6(1.3,10.2)$ \\
\hline Maximum tumor diameter (mm) & $15(10,22)$ \\
\hline
\end{tabular}

\begin{tabular}{c}
\hline Parhon, Romania $(n=87)$ \\
\hline 65.1 \\
$51.0(41.5,62.0)$ \\
$54.0(46.0,62.0)$ \\
$45.0(39.3,55.0)$ \\
$59.0(13.5,115.3)$ \\
$740(508,963)$ \\
$3.3(2.2,3.9)$ \\
$7.6(3.4,16.4)$ \\
$5.3(2.0,11.2)$ \\
$16(10,24)$ \\
\hline
\end{tabular}

\begin{tabular}{c}
$\begin{array}{c}\text { OHSU, United States } \\
(n=129)\end{array}$ \\
\hline 55.0 \\
$51.0(34.0,60.0)$ \\
$51.0(32.5,58.0)$ \\
$51.5(40.0,61.0)$ \\
$60.0(24.0,119.0)$ \\
$596(409,926)$ \\
$2.1(1.4,3.4)$ \\
$4.7(1.4,22.8)$ \\
$2.1(0.5,7.9)$ \\
$15(9,21)$
\end{tabular}

\begin{tabular}{c}
\hline p-value \\
\hline NS \\
NS \\
0.035 \\
NS \\
NS \\
0.07 \\
$<0.001$ \\
NS \\
0.007 \\
NS \\
\hline
\end{tabular}

All data are presented as median (25, 75 percentile) except females (percent)

$\mathrm{GH}$, growth hormone; IGF-1, insulin-like growth factor-1; NS, not significant; ULN, upper limit of normal.

(31.9\%), facial rounding (26.4\%), truncal obesity (25.5\%), skin thickening (23.6\%), hand edema (20.8\%), and goiter (17.1\%). Dental articulation problems, abnormal visual field, hirsutism, galactorrhea, arthropathy, husky voice, acne, plethora, acanthosis nigricans, hyperpigmentation, leg edema, and gynecomastia had an aggregate frequency of $<15 \%$ each. Figure 1 compares the frequencies of symptoms and the corresponding physical exam findings at Parhon vs OHSU (with an aggregate frequency of at least 20\%).

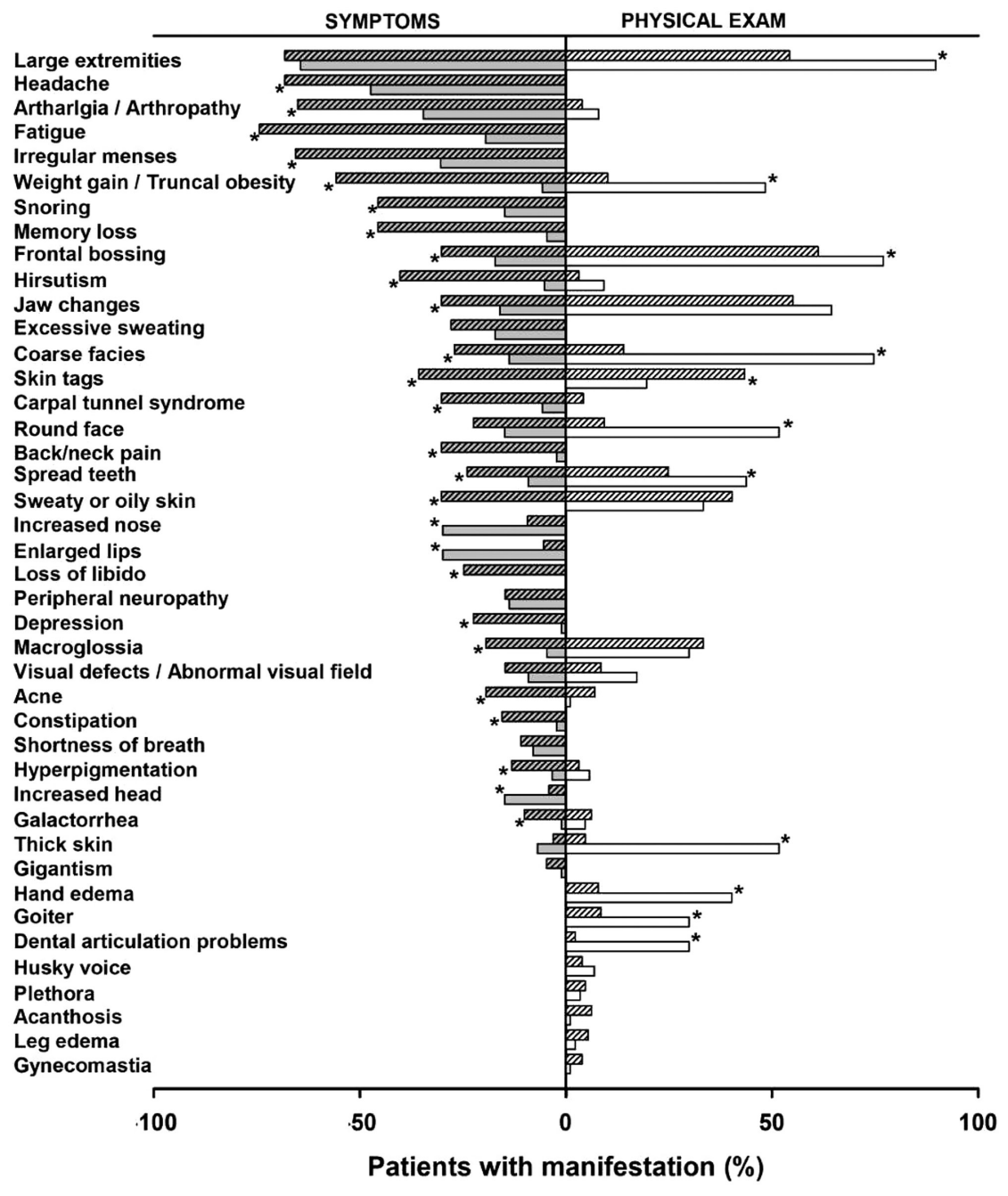

Figure 1

Reported symptoms (gray bars) and corresponding physical exam findings (white bars) in Parhon (clear bars) and OHSU patients (shaded bars). $* P<0.05$ between Parhon and OHSU patients. https://ec.bioscientifica.com https://doi.org/10.1530/EC-21-0035 (c) 2021 The authors Published by Bioscientifica Ltd
This work is licensed under a Creative Commons Attribution-NonCommercial-NoDerivatives 4.0 Internationab bicense.ifica . com at 04/26/2023 09:34:09Am 
A significant difference was found in multiple symptoms at presentation between the two centers (Fig. 1). Symptoms that were more commonly documented in OHSU patients included headache, arthralgia, fatigue, weight gain, snoring, memory and concentration problems, coarse facies, frontal bossing, jaw changes, spreading of the teeth, macroglossia, hirsutism, acne, oily skin, skin tags, hyperpigmentation, irregular menses, carpal tunnel syndrome (CTS), back and neck pain, loss of libido, depression, constipation, and galactorrhea. Nose enlargement, lip enlargement, and increased head size were more commonly documented in Parhon patients. There was no difference in documented frequency of enlarged extremities, excessive sweating, rounding of the face, peripheral neuropathy, thickening of the skin, visual defects, shortness of breath, and gigantism.

With regards to physical exam findings, hand enlargement, frontal bossing, coarse facies, gaps between the teeth, facial rounding, truncal obesity, skin thickening, hand edema, abnormal thyroid exam, and dental articulation problems were more frequently documented in Parhon patients, whereas skin tags were more frequently documented in OHSU patients (Fig. 1). There was no difference in documented protruding jaw, oily/sweaty skin, macroglossia, abnormal visual field, hirsutism, acne, galactorrhea, arthropathy, husky voice, facial plethora, acanthosis, hyperpigmentation, leg edema, and gynecomastia.

Logistic regression analysis was performed to determine which independent variables (center, age, sex, delay in diagnosis, IGF-1 index, and GH) could serve as predictors of reported symptoms and physical exam findings with an aggregate prevalence of at least $20 \%$ (Table 2). Patients at OHSU were more likely than patients at Parhon to report headache, arthralgia, fatigue, weight gain, snoring, memory/concentration problems, hirsutism, jaw changes, and carpal tunnel syndrome. Endocrinologists at OHSU were more likely to document skin tags, macroglossia, and hirsutism and less likely to document hand enlargement, coarse facies, gaps between the teeth, truncal obesity, skin thickening, and hand edema. Higher IGF-1 index predicted symptoms of enlarged extremities and protruding jaw and several physical exam findings (hand enlargement, frontal bossing, protruding jaw, sweaty/oilyskin, and macroglossia). Longer delay in diagnosis was the independent predictor only for symptom of hand enlargement and for physical findings of hand enlargement, protruding jaw, and truncal obesity; however, the odds ratio (OR) for this predictor was essentially 1 . When multiple predictors were retained in the regression model, the center had the highest impact based on the OR (Table 2).
Frequency of comorbidities before the diagnosis of acromegaly and total (at any time up until last follow-up) are presented in Fig. 2. We found the variable prevalence of comorbidities in patients at Parhon and OHSU; hypertension, hyperlipidemia, and DM/impaired glucose tolerance being most common at both centers. Numerically, hypertension, myocardial hypertrophy, and thyroid nodules were more prevalent at Parhon, while diabetes, sleep apnea, colonic polyps, and vertebral fractures were more prevalent at OHSU. Of note, the percent of patients screened with a sleep study, ECHO, x-rays, colonoscopy, and thyroid ultrasound differed considerably between the centers, contributing to the difference in the prevalence of comorbidities.

\section{Discussion}

To our knowledge, this is the first study to perform comparative analysis in two geographically and culturally different populations of patients with acromegaly. We assessed the clinical presentation of newly diagnosed acromegaly patients at two high volume academic Pituitary referral centers; one in Romania and one in the US and examined whether any differences noted were related to disease or other factors, such as medical practice, documentation, culture and, thus, center.

We demonstrated important differences, in both physical exam findings and symptoms, between acromegaly patients at the two centers. Notably, the top five symptoms at presentation were the same; (i) enlarged hands/feet, (ii) headache, (iii) arthralgia, (iv) fatigue, and (v) irregular menses in women. However, the frequency of these symptoms (except enlarged hands/feet) differed by $>20$ percentage points (enlarged hands/feet: $64.4 \%$ and $68.2 \%$; headache: $47.1 \%$ and $68.2 \%$; arthralgia: $34.6 \%$ and $65.1 \%$; fatigue: $19.5 \%$ and $74.4 \%$ and irregular menses in women $30.4 \%$ and $65.6 \%$ at Parhon and OHSU, respectively). This was observed in multiple other symptoms such that frequency of reported snoring, skin tags, weight gain, memory loss, or depression at OHSU was at least 20 percentage points higher than at Parhon. While reported increased size of nose and lips was at least 20 percentage points higher at Parhon. We also found differences in the physical exam findings, with a significantly higher prevalence of hand enlargement, coarse facies, gaps between teeth, facial rounding, skin thickening, and dental articulation problems at Parhon; at least 20 percentage points higher than at OHSU.

This work is licensed under a Creative Commons Attribution-NonCommercial-NoDerivatives 4.0 elnternational License.ifica, com at 04/26/2023 09:34:09AM 


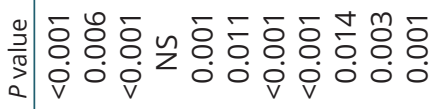

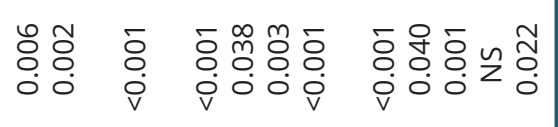

บ ทัษ

岁

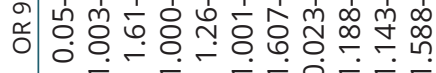

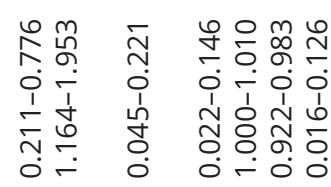

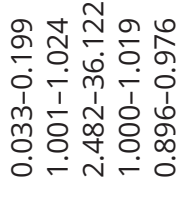

윤

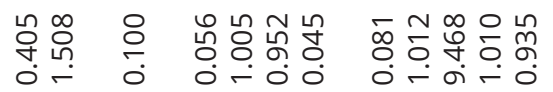

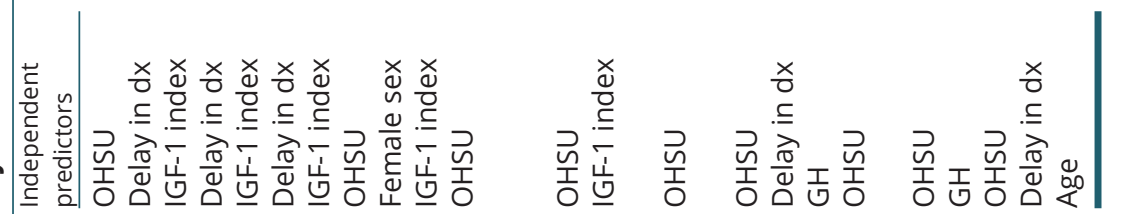

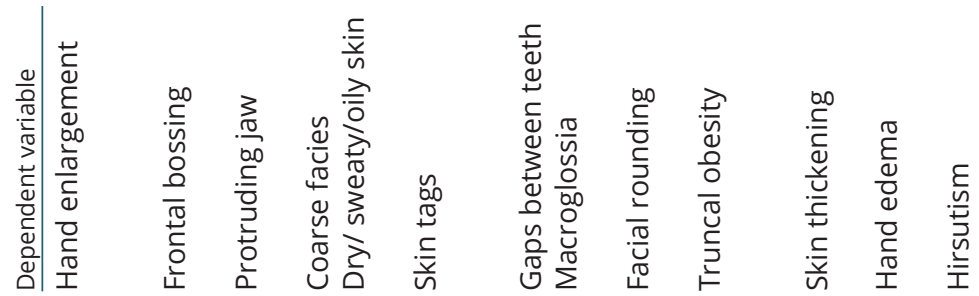

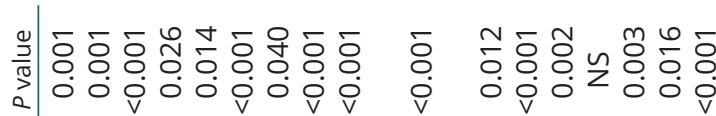

บ

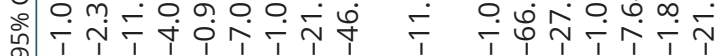

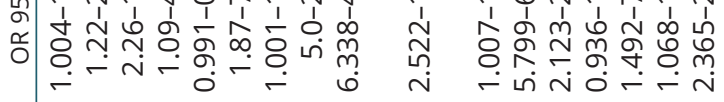

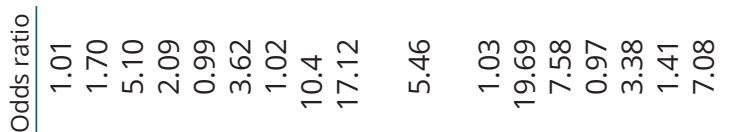

Z

है

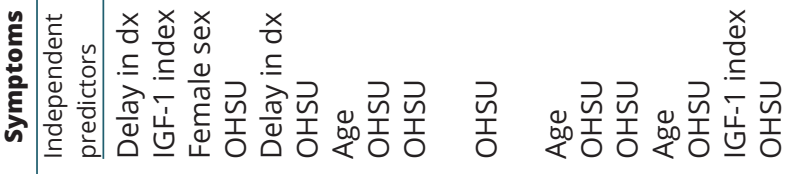

है
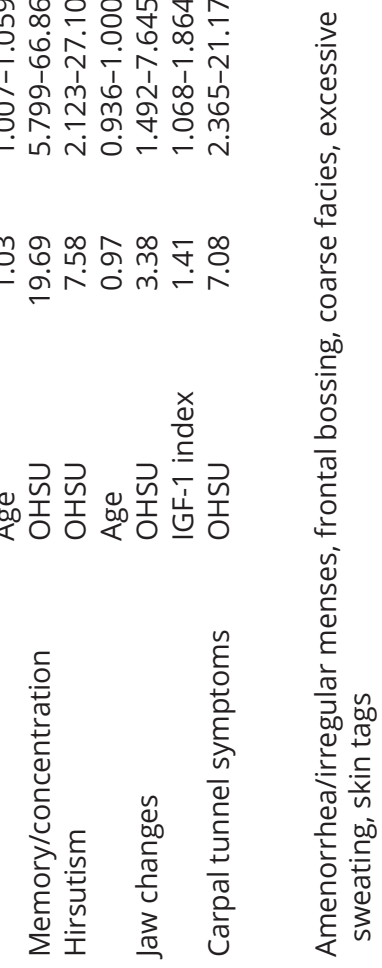
OHSU

Parhon

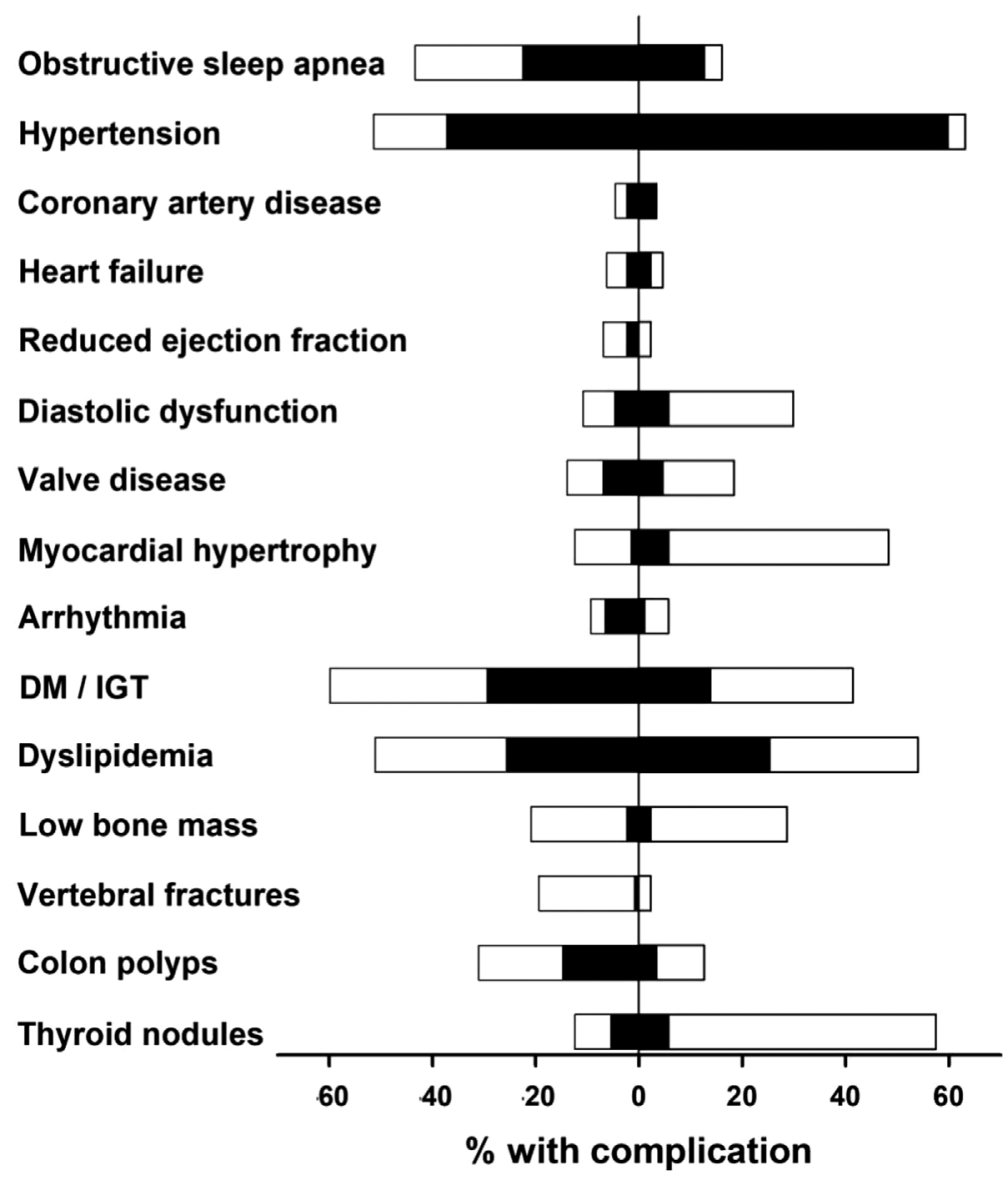

\begin{tabular}{|l|c|c|}
\cline { 2 - 3 } \multicolumn{1}{c|}{} & \multicolumn{2}{c|}{ Institution Evaluation Site } \\
\cline { 2 - 3 } \multicolumn{1}{c|}{} & OHSU & Parhon \\
\hline Comorbidity; n (\%) & & \\
\hline Evaluation for obstructive sleep apnea & $64(50)$ & $15(17)$ \\
\hline Echocardiogram & $117(69)$ & $40(46)$ \\
\hline Spinal x-rays & $85(66)$ & $7(8)$ \\
\hline Colonoscopy & $73(57)$ & $16(18)$ \\
\hline Thyroid ultrasound & $33(19)$ & $71(81)$ \\
\hline
\end{tabular}

\section{Figure 2}

Frequency of comorbidities at diagnosis (black bars) and at final assessment (white bars) in OHSU (left side) or Parhon (right side) patients. DM, diabetes mellitus; IGT, impaired glucose tolerance.
Multiple factors are likely responsible for such differences. While it is possible that genetic differences may affect the disease manifestation, this probably accounts for small differences. Sex and overall age distribution were similar at both centers. Interestingly, males were younger than females at Parhon but not at OHSU. Similarly, younger age at diagnosis in males has been observed in some (25) but not all studies $(13,25,26)$.

Among other factors, the severity and duration of disease may be responsible for some differences. We found that patients at Parhon had a worse biochemical disease, though similar delay in diagnosis as OHSU patients. However, this would not explain why the frequency of multiple symptoms was significantly higher at OHSU compared with Parhon. We suggest that cultural differences affecting patients' perception of their disease and recognition or validation of symptoms by physicians may explain some of the larger differences. Differences in the illness perception in different populations have been observed in different diseases and may be related not only to cultural but also to socio-economic, healthcare, and geographic differences $(18,20,21)$. Lastly, documentation of the symptoms, including the use of questionnaires and EMR templates vs manual symptoms entry could also likely create major differences in reporting of the symptoms. 
In the logistic regression analysis, we found that the respective center emerged as an important predictor, both positive and negative, of many signs and symptoms, independently of disease characteristics such as biochemical severity or disease duration. Patients at OHSU had a higher likelihood of reporting various symptoms, with the greatest odds found for reporting memory/concentration problems (19.69), weight gain (17.12), and fatigue (10.4). As these symptoms are not specific to acromegaly, the drastic difference between the centers suggests that there are major underlying differences in conducted clinical visits/interviews, clinical documentation, cultural and social characteristics of the studied populations.

Interestingly, our study showed important discrepancies between self-reported symptoms and their corresponding physical exam findings. As a general rule, the frequency of symptoms was lower than that of their corresponding signs. However, there were some exceptions such as reported frequency of arthralgia and hirsutism which was $65.1 \%$ and $40.3 \%$ but only $3.9 \%$ and $3.1 \%$ respectively at the physical exam documentation at OHSU (possibly due to lack of attention to the joint exam by physicians and hair removal by patients). The most important differences between signs and symptoms, $>20$ percentage points, were recorded for frontal bossing, jaw changes, coarse facies, round face, spread teeth, macroglossia, and skin thickening at Parhon. These differences between symptoms and signs are in accordance with previous studies (12) that demonstrated up to $40 \%$ differences at the time of first presentation. Some authors suggest that the perceived body changes in acromegaly are less related to objective findings at the physical exam but more related to depressive symptoms (27). A recent study of the oro-dental state in acromegalic patients also reported a discrepancy between a relatively good objective exam and unsatisfactory self-assessment of oral healthrelated QoL (28).

Prevalence of comorbidities was also drastically different between centers. This is likely largely related to the differences in the medical practices and implemented protocols for screening for comorbidities. For the evaluation of OSA, cardiomyopathy (ECHO), vertebral fractures, and colonoscopy is recommended for every acromegaly patient at OHSU, while thyroid ultrasound is performed on a needed basis as per guidelines (4, 29, 30) to prevent overdiagnosis of clinically irrelevant nodules. Conversely, at Parhon, thyroid ultrasound is performed essentially in every patient with a diagnosis of acromegaly in accordance with recommendations by some authors
(31) and the country's mild iodine deficiency $(32,33)$, thus, a much higher frequency of thyroid nodules was found. Myocardial hypertrophy was diagnosed by ECG or ECHO at Parhon, which could account for the higher frequency. Even prior to diagnosis, OSA and colonic polyps were observed more frequently at OHSU likely because of a higher number of sleep studies and colonoscopies performed in the general populations in the US at 50 years of age. Interestingly, while evaluation of hypertension, diabetes, and lipid disorders are likely similar, hypertension was more prevalent at Parhon, DM more prevalent at OHSU, and lipid disorders were similar in prevalence.

The cohort of patients examined here was similar to other cohorts from national or international databases. Median patient age was 51 years, similar to 51.9 years in the ACRO-POLIS study (12), 47 years in the German Registry (34), 45.2 years in the Liège Acromegaly Survey (LAS) database (5), and 46 years in a Canadian study (13). The percentage of females we report, 59.2\%, is slightly higher than the range 53-57.6\% reported in the above-mentioned studies $(5,12,13,34)$. Compared with registries that provided disease activity at diagnosis (35), our patients had lower $\mathrm{GH}$ values (5.7 vs $10 \mathrm{ng} / \mathrm{mL}$ ), a similar IGF-1 index (2.68 vs 2.77), and a similar tumor diameter $(15 \mathrm{~mm})$ (5). The top signs and symptoms recorded at diagnosis were similar to other studies $(12,13)$, with acral and facial morphological changes the most prevalent. However, frequencies vary across studies with acral enlargement reported in 55-100\% (this cohort, 66.7\%), sweating 52-91\% (this cohort, 23.6\%), and snoring/sleep apnea 7-81\% (this cohort, 32.9\%). This is likely explained by differences in clinical assessment, data documentation, and extraction.

Comorbidities reported prior to acromegaly diagnosis in our cohort were generally lower than those reported in the international LAS database (5) at diagnosis; however, there is significant heterogeneity of data collection in different studies (e.g. based on chart review vs diagnostic codes), which may in part be responsible for observed differences (Table 3$)(5,36,37)$. Importantly, the frequency of most commodities in this study almost doubled after screening, suggesting that targeted screening can improve the diagnosis of comorbidities and subsequent treatment. Comprehensive documentation templates might help keep track of acromegaly comorbidities in EMR and improve rates of assessment of comorbidities.

Taken together, our findings suggest that cultural and medical practice/documentation differences are important determinants of the clinical evaluation of acromegaly as demographics and disease characteristics remain merely

This work is licensed under a Creative Commons Attribution-NonCommercial-NoDerivatives 4.0 enternationad License.ifica com at 04/26/2023 09:34:09AM 
Table 3 Frequency of comorbidities in studies of geographically different cohorts.

\begin{tabular}{|c|c|c|c|c|}
\hline Comorbidities & $\begin{array}{l}\text { Present study (\% before } \\
\text { diagnosis } / \% \text { total) }\end{array}$ & $\begin{array}{l}\text { Petrossians et al. } \\
\text { (Europe) (5) }\end{array}$ & $\begin{array}{c}\text { Matsubayashi et } \boldsymbol{a l} . \\
\text { (Japan) (37) }\end{array}$ & $\begin{array}{l}\text { AlMalki et al. } \\
\text { (Saudi Arabia) (36) }\end{array}$ \\
\hline Hypertension (\%) & $46.2 / 55.5$ & 28.8 & 42.9 & 50 \\
\hline $\begin{array}{l}\text { Diabetes mellitus or impaired } \\
\text { glucose tolerance }(\%)\end{array}$ & $23.2 / 41.8$ & 29.6 & 37.1 & 51.7 \\
\hline Hyperlipidemia, (\%) & $24.45 / 52.5$ & - & 26.7 & - \\
\hline Myocardial hypertrophy (\%) & $3.2 / 26.8$ & 15.5 & - & - \\
\hline Sleep apnea (\%) & $18.9 / 32.4$ & 25.5 & 17.8 & 47.8 \\
\hline Colonic polyps (\%) & $10.1 / 23.6$ & 13 & - & 22.7 \\
\hline Thyroid nodules or goiter (\%) & $5.56 / 30.6$ & 34.0 & - & 37.5 \\
\hline
\end{tabular}

Comorbidity data were collected as follows: present study - OHSU and Parhon combined; chart review; \% before diagnosis/\% total; (5) Petrossians et al. - international database; \% at diagnosis; (29) Matsubayashi et al. - diagnostic codes in national database; \% before diagnosis; (30) AlMalki et al. - chart review; \% total before and after diagnosis.

constant across countries (5). As a result, the pooling of data on signs and symptoms in international registries (5) might lead to a loss of equally important regional characteristics. Additionally, it is possible that diagnosis instruments like ACROSCORE (14), which includes specific symptoms and comorbidities (colonic polyps, thyroid hyperplasia, and diabetes mellitus), may not be applicable in populations other than in those for which they were developed. The results we present also suggest that symptoms included in specific instruments, such as SAGIT (38) and ACRODAT (39), designed to assess disease control and disease activity and may need to be assessed by specific local questionnaires as perceived intensity could be different from one patient population to another.

The study has some limitations due to retrospective design, relatively small sample size per center, heterogeneous reporting of the data, and absence of a uniform questionnaire for every patient. This has a potential to 'miss' some symptoms and signs; however, we believe that given the centers' experience (both are large Pituitary Centers of excellence (40)) in treating patients with acromegaly, the number of clinical features present but not documented should be small. Also, this furthermore highlights the differences between centers in the real world.

Future studies should focus on clinical presentation between populations using standardized comprehensive questionnaires and a cross-sectional design at the initial evaluation by an endocrinologist. We hypothesize that such a study might demonstrate more similar frequencies of symptoms and signs between the populations. However, this might 'erase' some of the differences related to an individual's perception of the disease. While the patients in different regions may have similar symptoms and signs, the way they relay their symptoms to the physicians and the way physicians collect the information may be different due to cultural, socio-economic, and other factors.
In conclusion, we show important differences in symptoms, signs, and complications of acromegaly at diagnosis between university referral centers that are not associated with differences in disease characteristics $(\mathrm{GH}$, IGF-1, or tumor size). These suggest that local medical practice, EMR documentation, and cultural and possible socio-economic differences cannot be overlooked when various cohorts of patients with acromegaly are compared. We believe that understanding and addressing diversity and socio-economic differences can improve medical care. Targeted screening for comorbidities may improve assessment for comorbidities.

\section{Declaration of interest}

$\mathrm{M} F$ reports serving as an investigator with research grants to Oregon Health \& Science University (OHSU) for Chiasma, Crinetics, Ionis, Novartis and serving as an occasional consultant to Chiasma, Crinetics, Ionis, Ipsen, Pfizer, Recordati. C P has received research funding to Carol Davila University of Medicine and Pharmacy as a Principal Investigator from Novartis. The other authors have no conflict of interest to report.

\section{Funding}

This work did not receive any specific grant from any funding agency in the public, commercial, or not-for-profit sector.

\section{Ethical approval}

This retrospective chart review study involving human participants was in accordance with the ethical standards of the institutional research committees and with the 1964 Helsinki Declaration and its later amendments or comparable ethical standards. The OHSU and C. I. Parhon National Institute of Endocrinology Institutional Review Boards approved the data collection.

\section{Informed consent}

Institutional Review Board approval with a waiver of informed consent for this two-institution, retrospective, HIPAA-compliant study was obtained.

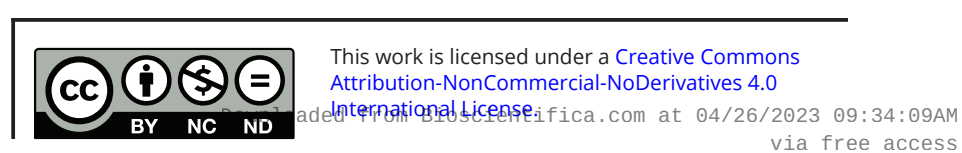




\section{Acknowledgement}

The authors thank Shirley McCartney, PhD, OHSU for editorial assistance and Madeleine Stack, BS for assistance with data collection.

\section{References}

1 Melmed S. Pituitary-tumor endocrinopathies. New England Journal of Medicine 2020382 937-950. (https://doi.org/10.1056/NEJMra1810772)

2 Ben-Shlomo A \& Melmed S. Acromegaly. Endocrinology and Metabolism Clinics of North America 200837 101-122. (https://doi.org/10.1016/j. ecl.2007.10.002)

3 Melmed S. Acromegaly pathogenesis and treatment. Journal of Clinical Investigation 2009119 3189-3202. (https://doi.org/10.1172/JCI39375)

4 Gadelha MR, Kasuki L, Lim DST \& Fleseriu M. Systemic complications of acromegaly and the impact of the current treatment landscape: an update. Endocrine Reviews 201940 268-332. (https://doi.org/10.1210/ er.2018-00115)

5 Petrossians P, Daly AF, Natchev E, Maione L, Blijdorp K, SahnounFathallah M, Auriemma R, Diallo AM, Hulting AL, Ferone D, et al. Acromegaly at diagnosis in 3173 patients from the liège acromegaly survey (las) database. Endocrine-Related Cancer 201724 505-518. (https://doi.org/10.1530/ERC-17-0253)

6 Alexander L, Appleton D, Hall R, Ross WM \& Wilkinson R. Epidemiology of acromegaly in the Newcastle region. Clinical Endocrinology 198012 71-79. (https://doi. org/10.1111/j.1365-2265.1980.tb03135.x)

7 Bengtsson BA, Eden S, Ernest I, Oden A \& Sjogren B. Epidemiology and long-term survival in acromegaly. A study of 166 cases diagnosed between 1955 and 1984. Acta Medica Scandinavica 1988223 327-335. (https://doi.org/10.1111/j.0954-6820.1988.tb15881.x)

8 Nabarro JD. Acromegaly. Clinical Endocrinology 198726 481-512. (https://doi.org/10.1111/j.1365-2265.1987.tb00805.x)

9 Reid TJ, Post KD, Bruce JN, Nabi Kanibir M, Reyes-Vidal CM \& Freda PU. Features at diagnosis of 324 patients with acromegaly did not change from 1981 to 2006: acromegaly remains under-recognized and under-diagnosed. Clinical Endocrinology 201072 203-208. (https://doi.org/10.1111/j.1365-2265.2009.03626.x)

10 Nachtigall L, Delgado A, Swearingen B, Lee H, Zerikly R \& Klibanski A. Changing patterns in diagnosis and therapy of acromegaly over two decades. Journal of Clinical Endocrinology and Metabolism 200893 2035-2041. (https://doi.org/10.1210/jc.2007-2149)

11 Kreitschmann-Andermahr I, Siegel S, Kleist B, Kohlmann J, Starz D, Buslei R, Koltowska-Haggstrom M, Strasburger CJ \& Buchfelder M. Diagnosis and management of acromegaly: the patient's perspective. Pituitary 201619 268-276. (https://doi.org/10.1007/s11102-015-0702-1)

12 Caron P, Brue T, Raverot G, Tabarin A, Cailleux A, Delemer B, Renoult PP, Houchard A, Elaraki F \& Chanson P. Signs and symptoms of acromegaly at diagnosis: the physician's and the patient's perspectives in the ACRO-POLIS study. Endocrine 201963 120-129. (https://doi.org/10.1007/s12020-018-1764-4)

13 Ezzat S, Forster MJ, Berchtold P, Redelmeier DA, Boerlin V \& Harris AG. Acromegaly: clinical and biochemical features in 500 patients. Medicine 199473 233-240. (https://doi.org/10.1097/00005792199409000-00001)

14 Prencipe N, Floriani I, Guaraldi F, Di Giacomo SV, Cannavo S, Arnaldi G, Berton A, Torri V, Spinello M, Arvat E, et al. ACROSCORE: a new and simple tool for the diagnosis of acromegaly, a rare and underdiagnosed disease. Clinical Endocrinology 201684 380-385. (https://doi.org/10.1111/cen.12959)

15 Holdaway IM \& Rajasoorya C. Epidemiology of acromegaly. Pituitary 19992 29-41. (https://doi.org/10.1023/a:1009965803750)

16 Maione L \& Chanson P. National acromegaly registries. Best Practice and Research: Clinical Endocrinology and Metabolism 201933101264. (https://doi.org/10.1016/j.beem.2019.02.001)
17 Colao A, Vandeva S, Pivonello R, Grasso LFS, Nachev E, Auriemma RS Kalinov K \& Zacharieva S. Could different treatment approaches in acromegaly influence life expectancy? A comparative study between Bulgaria and Campania (Italy). European Journal of Endocrinology 2014 171 263-273. (https://doi.org/10.1530/EJE-13-1022)

18 Erbil P, Razavi D, Farvacques C, Bilge N, Paesmans M \& Van Houtte P. Cancer patients psychological adjustment and perception of illness: cultural differences between belgium and turkey. Supportive Care in Cancer 19964 455-461. (https://doi.org/10.1007/BF01880644)

19 Jongen C, McCalman J, Bainbridge R \& Clifford A. Cultural Competence in Health: A Review of the Evidence, Vol. XIV, p. 139. Singapore: Springer, 2018.

20 Putrik P, Ramiro S, Hifinger M, Keszei AP, Hmamouchi I, Dougados M, Gossec L \& Boonen A. In wealthier countries, patients perceive worse impact of the disease although they have lower objectively assessed disease activity: results from the cross-sectional COMORA study. Annals of the Rheumatic Diseases 201675 715-720. (https://doi. org/10.1136/annrheumdis-2015-207738)

21 Ruiz-Montero PJ, Van Wilgen CP, Segura-Jimenez V, Carbonell-Baeza A \& Delgado-Fernandez M. Illness perception and fibromyalgia impact on female patients from Spain and the Netherlands: do cultural differences exist? Rheumatology International 201535 1985-1993. (https://doi.org/10.1007/s00296-015-3281-6)

22 Fleseriu M, Biller BMK, Freda PU, Gadelha MR, Giustina A, Katznelson L, Molitch ME, Samson SL, Strasburger CJ, van der Lely AJ, et al. A pituitary society update to acromegaly management guidelines. Pituitary 202124 1-13. (https://doi.org/10.1007/s11102-020-01091-7)

23 Niculescu DA, Baciu IF, Capatina C, Galoiu SA, Gheorghiu ML, Radian S, Trifanescu RA, Caragheorgheopol A, Coculescu M \& Poiana C. Acromegaly treatment in Romania. How close are we to disease control? Endokrynologia Polska 201768 519-523. (https://doi. org/10.5603/EP.a2017.0041)

24 Varlamov EV, Wood MD, Netto JP, Thiessen J, Kim J, Lim DST, Yedinak CG, Banskota S, Cetas JS \& Fleseriu M. Cystic appearance on magnetic resonance imaging in bihormonal growth hormone and prolactin tumors in acromegaly. Pituitary 202023 672-680. (https:// doi.org/10.1007/s11102-020-01075-7)

25 Lenders NF, McCormack AI \& Ho KKY. Management of endocrine disease: does gender matter in the management of acromegaly? European Journal of Endocrinology 2020182 R67-R82. (https://doi. org/10.1530/EJE-19-1023)

26 Agustsson TT, Baldvinsdottir T, Jonasson JG, Olafsdottir E, Steinthorsdottir V, Sigurdsson G, Thorsson AV, Carroll PV, Korbonits M \& Benediktsson R. The epidemiology of pituitary adenomas in Iceland, 1955-2012: a nationwide population-based study. European Journal of Endocrinology 2015173 655-664. (https://doi.org/10.1530/ EJE-15-0189)

27 Dimopoulou C, Leistner SM, Ising M, Schneider HJ, Schopohl J, Rutz S, Kosilek R, Frohner R, Stalla GK \& Sievers C. Body image perception in acromegaly is not associated with objective acromegalic changes but depends on depressive symptoms. Neuroendocrinology 2017105 115-122. (https://doi.org/10.1159/000448519)

28 Roumeau S, Thevenon J, Ouchchane L, Maqdasy S, Batisse-Lignier M, Duale C, Pham Dang N, Caron P, Tauveron I \& Devoize L. Assessment of oro-dental manifestations in a series of acromegalic patients, the acrodent study. Endocrine Connections 20209 824-833. (https://doi. org/10.1530/EC-20-0176)

29 Katznelson L, Laws ER, Jr, Melmed S, Molitch ME, Murad MH, Utz A, Wass JA \& Endocrine Society. Acromegaly: an Endocrine Society clinical practice guideline. Journal of Clinical Endocrinology and Metabolism 201499 3933-3951. (https://doi.org/10.1210/jc.2014-2700)

30 Melmed S, Bronstein MD, Chanson P, Klibanski A, Casanueva FF, Wass JAH, Strasburger CJ, Luger A, Clemmons DR \& Giustina A. A consensus statement on acromegaly therapeutic outcomes. Nature Reviews. Endocrinology 201814 552-561. (https://doi.org/10.1038/ s41574-018-0058-5) 
31 Terzolo M, Puglisi S, Reimondo G, Dimopoulou C \& Stalla GK. Thyroid and colorectal cancer screening in acromegaly patients: should it be different from that in the general population? European Journal of Endocrinology 2020183 D1-D13. (https://doi.org/10.1530/EJE-19-1009)

32 Ursu HI, Toader OD, Podia-Igna C, Delia CE, Firta AR, Tupea CC, Tudor LM, Gheorghiu ML \& Suciu N. Iodine status in pregnant women after a decade of universal salt iodization in Romania. Acta Endocrinologica 201612 161-167. (https://doi.org/10.4183/ aeb.2016.161)

33 Simescu M, Dumitriu L, Sava M, Ciovernache D, Colda A, Balmes E, Ursu H, Bistriceanu M, Zosin I \& Duncea I. Urinary iodine levels in schoolchildren and pregnant women after the legislative changes in the salt iodization. Acta Endocrinologica 20062 33-44. (https://doi. org/10.4183/aeb.2006.33)

34 Schofl C, Franz H, Grussendorf M, Honegger J, Jaursch-Hancke C, Mayr B, Schopohl J, participants of the German Acromegaly Register, Bender G \& Berg C. Long-term outcome in patients with acromegaly: analysis of 1344 patients from the German Acromegaly Register European Journal of Endocrinology 2013 168 39-47. (https://doi. org/10.1530/EJE-12-0602)

35 Fieffe S, Morange I, Petrossians P, Chanson P, Rohmer V, Cortet C, Borson-Chazot F, Brue T, Delemer B \& French Acromegaly Registry. Diabetes in acromegaly, prevalence, risk factors, and evolution: data from the French Acromegaly Registry. European Journal of Endocrinology 2011164 877-884. (https://doi.org/10.1530/EJE-10-1050)
36 AlMalki MH, Ahmad MM, Buhary BM, Aljawair R, Alyamani A, Alhozali A, Alshahrani A, Alzahrani S, Nasser T, Alzahrani W, et al. Clinical features and therapeutic outcomes of patients with acromegaly in Saudi Arabia: a retrospective analysis. Hormones 202019 377-383. (https://doi.org/10.1007/s42000-020-00191-0)

37 Matsubayashi K \& Kawakami K. Prevalence, incidence, comorbidities, and treatment patterns among Japanese patients with acromegaly: a descriptive study using a nationwide claims database. Endocrine Journal 202067 997-1006. (https://doi.org/10.1507/endocrj.EJ20-0129)

38 Giustina A, Bevan JS, Bronstein MD, Casanueva FF, Chanson P, Petersenn S, Thanh XM, Sert C, Houchard A, Guillemin I, et al. SAGIT(R): clinician-reported outcome instrument for managing acromegaly in clinical practice - development and results from a pilot study. Pituitary 201619 39-49. (https://doi.org/10.1007/s11102-0150681-2)

39 van der Lely AJ, Gomez R, Pleil A, Badia X, Brue T, Buchfelder M, Burman P, Clemmons D, Ghigo E, Jorgensen JOL, et al. Development of ACRODAT((R)), a new software medical device to assess disease activity in patients with acromegaly. Pituitary 201720 692-701. (https://doi. org/10.1007/s11102-017-0835-5)

40 Casanueva FF, Barkan AL, Buchfelder M, Klibanski A, Laws ER, Loeffler JS, Melmed S, Mortini P, Wass J, Giustina A, et al. Criteria for the definition of pituitary tumor centers of excellence (PTCOE): a pituitary society statement. Pituitary 201720 489-498. (https://doi. org/10.1007/s11102-017-0838-2)

Received in final form 13 May 2021

Accepted 3 June 2021

Accepted Manuscript published online 7 June 2021
(C) 2021 The authors Published by Bioscientifica Ltd
This work is licensed under a Creative Commons Attribution-NonCommercial-NoDerivatives 4.0

Internationad License ifica com at 04/26/2023 09:34:09AM 